\title{
Antidepressant-Induced Mood Conversions in Bipolar Disorder: A Retrospective Study of Tricyclic versus Non-Tricyclic Antidepressant Drugs
}

\author{
Iwona Koszewska ${ }^{a} \quad$ Janusz K. Rybakowski ${ }^{b}$ \\ ${ }^{a}$ Affective Disorder Unit, 2nd Department of Psychiatry, Institute of Psychiatry and Neurology, Warsaw, and \\ ${ }^{b}$ Department of Adult Psychiatry, Poznan University of Medical Sciences, Poznan, Poland
}

\section{Key Words}

Bipolar illness • Depression • Mania · Mood conversion •

Antidepressants, tricyclic

\begin{abstract}
Objectives: The aim of this retrospective study was an analysis of antidepressant-induced mood conversions to mania/ hypomania occurring in bipolar inpatients treated with antidepressants in the Affective Disorder Unit of the Institute of Psychiatry and Neurology, Warsaw, in the years 1972-1996. Methods: The data for analysis were obtained retrospectively from clinical records. In a subgroup of patients prone to mood conversions, a comparison was done of depressive episodes treated with antidepressants with and without a switch to mania/hypomania as well as the frequency of mood conversions induced by particular antidepressant drugs, especially tricyclic (TCA) versus non-TCA drugs. $\boldsymbol{R e}$ sults: Among 333 bipolar patients hospitalized in this period, mood conversions were observed in 118 subjects, significantly more frequently in female $(44 \%)$ than in male patients (25\%), and in patients with depressive episode at the onset of illness ( 80 vs. $40 \%$ ). Among mood converters, it was found that the depressive episodes with a switch to mania were less severe, shorter, and with shorter duration of antidepressant treatment. The risk of switching was higher during treatment with TCA than with non-TCA drugs (36 vs. $17 \%)$, the highest with amitriptyline (42\% of treated epi-
\end{abstract}

sodes), imipramine (40\%) and clomipramine (35\%). Conclusions: Our results suggest that bipolar patients prone to mood conversion constitute one third of the inpatient population with this illness. The switch from depression to mania occurred significantly more frequently during treatment with TCA than with non-TCA drugs. It is hypothesized that anticholinergic activity may contribute to the higher frequency of TCA-induced mood conversions.

Copyright $\odot 2009$ S. Karger AG, Basel

\section{Introduction}

Since the introduction of antidepressant drugs (ADs) into the treatment of bipolar disorder (BD), a number of papers have appeared describing the so-called AD-induced mania. Wehr and Goodwin [1] postulated that tricyclic antidepressants (TCAs) could induce mania or hypomania and rapid cycling, and so worsen the course of $\mathrm{BD}$ by accelerating cycle frequency. In a more recent study, Goldberg and Truman [2] reported that about one quarter to one third of bipolar patients may be inherently susceptible to $\mathrm{AD}$-induced mania. In about $20-40 \%$ of bipolar patients, AD-induced mania/hypomania has been reported for all major AD classes. Evidence supports an increased risk in patients with early onset of illness, bipolar family history, exposure to multiple $\mathrm{AD}$ treatments and previous $\mathrm{AD}$-induced manias. Chun and

\section{KARGER}

Fax +41613061234 E-Mail karger@karger.ch www.karger.com (c) 2009 S. Karger AG, Basel

0302-282X/09/0591-0012\$26.00/0

Accessible online at:

www.karger.com/nps
Dr. Iwona Koszewska, MD, PhD

Affective Disorder Unit, 2nd Department of Psychiatry

Institute of Psychiatry and Neurology

Al. Sobieskiego 9, PL-02-957 Warsaw (Poland)

Tel. +48 22 4582 764, Fax +48 224582 850, E-Mail koszewi@ipin.edu.pl 
Dunner [3] claim that it should not be a separate category because 'antidepressant-associated hypomania' belongs to the course of $\mathrm{BD}$.

Contrary to the above findings and based on 6 decades of different treatments, Angst [4] presented evidence that the rate of switching was the same (29\%) for patients with $\mathrm{BD}$ untreated and treated by different agents. Coryell et al. [5] prospectively studied 345 patients and did not find any association between the use of ADs and a switch from depression to mania. In a systematic review and metaanalysis of the $\mathrm{AD}$-induced switch rate in $\mathrm{BD}$, no evidence has been shown of an increased risk of switching depression during AD therapy to manic episodes [6]. The conclusion from the study by Carslon et al. [7] is that in the sample with severe BD switching from depression to mania was not associated with AD treatment. Nevertheless, the current guidelines recommend a restricted use of ADs in the treatment of bipolar depression. Furthermore, the clinical efficacy of ADs in bipolar depression has been questioned. In a recent study, the use of adjunctive $\mathrm{AD}$ medication in bipolar depression concurrent with mood stabilizers was not associated with increased antidepressant efficacy or increased risk of affective switch [8].

On the other hand, there has been consensus about the higher risk of inducing mania or hypomania during treatment with TCA than with non-TCA drugs [9]. Peet [10] has shown that in bipolar patients manic switches occurred substantially more often with TCAs than with selective serotonin re-uptake inhibitors (SSRIs) or placebo (11.2 vs. 3.7 vs. $4.2 \%)$. Other studies gave even higher figures for manic switches on TCAs (30-70\%) than on SSRIs (15-27\%) and noted that TCA-induced manias appeared to be more intense than switches related to other ADs [1114]. Stoll et al. [15] found that tricyclics and fluoxetine were more frequently associated with subsequent mania than monoamine oxidase inhibitors or bupropion. Sachs et al. [16] found a switch rate in the TCA group five times higher than that in the bupropion group over a 1-year follow-up period (50 vs. 11\%). Gijsman et al. [6] concluded that the patients who are perceived as being at risk for switching to mania should be treated with SSRIs rather than TCAs. In their study, the rate of switching for TCAs was $10 \%$ and for all other ADs $3 \%$, for placebo $4.7 \%$. Ghaemi et al. [17] suggested that the risk of acute manic switch rates in the short term is around $40 \%$ with TCAs and $20 \%$ with newer ADs, and the majority of switches on $\mathrm{AD}$ usually occurred in the first 10-16 weeks of treatment.

The aim of this study is a retrospective analysis of $\mathrm{AD}$ induced mood conversions occurring in bipolar inpatients treated with ADs in the years 1972-1996. This pe- riod was chosen for the analysis because treatment strategies during this time were not affected by contemporary standards requiring the avoidance of excessive use of ADs in bipolar patients and a small number of mood-stabilizing treatments.

\section{Method}

The data for analysis were obtained retrospectively from clinical records of the Affective Disorder Unit of the Institute of Psychiatry and Neurology for the period 1972-1996. They included demographic and clinical features as well as psychotropic (particularly AD) treatment. The ICD-IX criteria for BD were used. The project was approved by the Bioethics Committee of the Institute.

The mood conversion (switch from depression to mania) was defined as a direct change (without a remission period) of a depressive episode into a manic (or hypomanic) one. The manic or hypomanic episode should meet DSM-IV symptomatic criteria [18], with the duration of symptoms lasting at least 4 days.

In a subgroup of patients prone to mood conversions, two kinds of analyses were done: (1) comparison of depressive episodes treated with ADs with and without mood conversions, and (2) comparison of the frequency of mood conversions induced by particular ADs, especially TCAs versus non-TCAs.

In statistical analyses $\chi^{2}$ and tests were used to examine the statistical significance of differences between the respective groups.

\section{Results}

At the unit 333 bipolar inpatients (130 males, $193 \mathrm{fe}$ males) were treated with ADs in the period 1972-1996. Among them, there were 118 ( 33 male, 85 female) subjects (35\%) in whom mood conversion (switch from depression to mania during hospitalization) occurred. The ages of both groups were similar: $56 \pm 13$ years in non-switchers and $55 \pm 14$ years in switchers. Both groups did not differ with regard to age at onset, duration of illness, and family history of mood disorder. The percentage of patients with mood conversion was significantly higher among female than among male patients ( 44 vs. $25 \%, \mathrm{p}<0.001, \chi^{2}$ test). The only clinical difference was the polarity of the first episode: the beginning of illness with depression was significantly more frequent in switchers than in non-switchers ( 80 vs. $40 \%, p<0.001, \chi^{2}$ test). The difference between male and female switchers was a greater number of depressive episodes in female than in male patients.

In the 118 switchers there were 371 depressive episodes, of which 323 were treated with ADs. Among them 210 depressive episodes (65\%) converted to mania. A comparison of depressive episodes treated with ADs in 
Table 1. Clinical and pharmacological data for depressive episodes treated with antidepressants, terminated with mania or recovery

\begin{tabular}{|c|c|c|c|}
\hline \multirow[t]{2}{*}{ Variable } & \multicolumn{2}{|c|}{ All episodes treated with antidepressants $(n=323)$} & \multirow[t]{2}{*}{ Difference } \\
\hline & switch to mania $(\mathrm{n}=210)$ & no switch to mania $(\mathrm{n}=113)$ & \\
\hline Duration of depression until the start of the treatment, days & $74.1 \pm 108.4$ & $63.3 \pm 67.0$ & NS \\
\hline Duration of treatment with antidepressants, days & $59.4 \pm 50.9$ & $135.4 \pm 152.5$ & $\mathrm{p}<0.001$ \\
\hline Duration of depression, months & $4.4 \pm 4.2$ & $6.6 \pm 5.1$ & $\mathrm{p}<0.05$ \\
\hline Number of antidepressants & $1.9 \pm 1.4$ & $2.4 \pm 1.6$ & $\mathrm{p}<0.01$ \\
\hline \multicolumn{4}{|l|}{ Intensity of depression } \\
\hline Severe & $97(46 \%)$ & $68(60 \%)$ & \multirow[t]{3}{*}{$\mathrm{p}<0.05$} \\
\hline Moderate & $109(52 \%)$ & $44(39 \%)$ & \\
\hline Mild & $4(2 \%)$ & $1(1 \%)$ & \\
\hline Mood stabilizing treatment longer than 6 months & $9(4.3 \%)$ & $6(5.3 \%)$ & NS \\
\hline Life events until depression & $8(4 \%)$ & $4(3.5 \%)$ & NS \\
\hline CNS or serious somatic disorders prior to depression & $26(12 \%)$ & $8(7 \%)$ & NS \\
\hline
\end{tabular}

The values are given as means \pm SD or numbers with percentages in parentheses. NS $=$ Not significant.

this group with or without manic switch is presented in table 1 .

The duration of the episode until the start of treatment with an $\mathrm{AD}$ was similar in both groups. However, the depressive episodes converting to mania were treated with ADs for a shorter time, used a smaller number of different ADs, had a shorter duration, and were less severe. Treatment with mood stabilizers (longer than half a year), life events, somatic or CNS disorders were not significantly different between the 2 groups.

In 323 depressive episodes, the total of $534 \mathrm{AD}$ treatments (in some episodes more than one treatment) was implemented. The following antidepressants were used: amitriptyline ( $\mathrm{n}=193)$; imipramine $(\mathrm{n}=88)$; clomipramine $(\mathrm{n}=39)$; dibenzepin $(\mathrm{n}=35)$; doxepin $(\mathrm{n}=35)$; noxiptyline $(\mathrm{n}=20)$; maprotiline $(\mathrm{n}=18)$; azaphen $(\mathrm{n}=16)$; desipramine $(\mathrm{n}=11)$; nomifensine $(\mathrm{n}=11)$; trazodone $(\mathrm{n}=11)$; mianserin $(\mathrm{n}=10)$; fluoxetine $(\mathrm{n}=9)$; amoxapine $(\mathrm{n}=8)$; fluvoxamine $(\mathrm{n}=8)$; nortriptyline $(\mathrm{n}=$ 5); paroxetine $(\mathrm{n}=4)$; viloxazine $(\mathrm{n}=3)$; moclobemide $(\mathrm{n}=3)$; melitracene $(\mathrm{n}=3)$; selegiline $(\mathrm{n}=2)$, and tianeptine $(\mathrm{n}=2)$. The comparison of inducing mood conversions was performed between 457 different TCA treatments and 77 different non-TCA treatments. The results (separately for male and female patients) are presented in table 2.

The risk of $\mathrm{AD}$-induced mania was significantly greater when TCAs were used, compared with treatment with non-TCAs (36 vs. $17 \%, \mathrm{p}<0.001$ ). In this group of patients who used ADs 10 times or more, mood conversions occurred most frequently with amitriptyline (42\%), imipramine (40\%), clomipramine (35\%), dibenzepin (26\%) and
Table 2. Antidepressant treatment of depressive episodes with or without mood conversions

\begin{tabular}{lllc} 
Treatment & \multicolumn{3}{c}{ Antidepressants treatments } \\
\cline { 2 - 4 } & all, $\mathrm{n}$ & $\begin{array}{l}\text { switch to } \\
\text { mania, } \mathrm{n}\end{array}$ & $\begin{array}{l}\text { no switch } \\
\text { to mania, } \mathrm{n}\end{array}$ \\
\hline All & 534 & $176(33 \%)$ & $358(77 \%)$ \\
TCA vs. non-TCA drugs & $457: 77$ & $12.5: 1$ & $4.6: 1$ \\
TCA treatments & 457 & $163(36 \%)$ & $294(64 \%)$ \\
$\quad$ Female & 326 & 117 & 209 \\
$\quad$ Male & 131 & 46 & 85 \\
Non-TCA treatments & 77 & $13(17 \%)$ & $64(83 \%)$ \\
$\quad$ Female & 55 & 9 & 46 \\
$\quad$ Male & 22 & 4 & 18
\end{tabular}

* Difference between TCA and non-TCA drugs significant: $\mathrm{p}<0.001$.

doxepin (26\%) and less frequently with mianserin (1/10) and maprotiline (1/18). There was no difference between female and male patients in the percentage of switches on different groups of ADs.

\section{Discussion}

Goldberg and Truman [2] reported that about one quarter to one third of bipolar patients may be inherently susceptible to $\mathrm{AD}$-induced mania. Our retrospective 
analysis shows that approximately one third of bipolar patients has a tendency to mood conversion, with a significant preponderance of female patients and patients in whom the illness began with a depressive episode. This result is similar to other studies on the frequency of mood conversion in $\mathrm{BD}$ during the natural course of the illness [11]. Most of the studies [4, 19], but not all [14], also link the phenomenon of switching with female gender.

Analysis of the mood converter group brought about some findings concerning the clinical character of the depressive episode ending with a switch to mania as well as the frequency of mood conversion during treatment with various ADs. There was no significant difference between the duration of depressive episodes with and without switch until the start of treatment. However, the total period of treatment with ADs was significantly shorter in episodes ending with mania than in those without the switch. This suggests that $\mathrm{AD}$-induced mania is not related to the duration of treatment with ADs. Our results also show that the most susceptible period for manic switch is in the initial phase of $\mathrm{AD}$ treatment when the depressive episode is not very severe, corresponding to the results of Ghaemi et al. [17].

In our study, pharmacotherapy with TCA was associated with a more than double risk of manic switch than non-TCA drugs (36 and 17\%, respectively), without differences between females and males. These figures are slightly higher than those obtained in recent studies. For instance, Peet [10], in his meta-analysis of the bipolar group taking SSRIs, found that the switch rate was not significantly different from that in the placebo group (about 4\%) and significantly lower than the 11\% switch rate reported in studies involving TCAs. However, it should be mentioned that our group consisted of only one third of the bipolar population so our results should be divided by three, i.e. TCA vs. non-TCA could be 12 vs. $6 \%$, more similar to the findings of Peet [10].

The pharmacological mechanisms of $\mathrm{AD}$-induced manic switch are still subject to debate. According to an early study by Bunney [20], catecholaminergic rather than serotonergic mechanisms are implicated in manic switching. Subsequent studies brought about the strongest pharmacological support for the dopaminergic system among all the neurotransmitter systems with regard to the potential involvement in the switch process [21].

In 1991, Koszewska and Pużyński [22] suggested the important role of the cholinergic system in the pathophysiology of mood conversion in $\mathrm{BD}$. This was confirmed in the present study where the highest risk of switch (more than 30\%) was observed with the use of am-
Table 3. Frequency (\%) of antidepressant-induced switching to mania in patients with bipolar illness and equilibrium dissociation constants for muscarinic acetylcholine receptors of human brain

\begin{tabular}{lll}
\hline $\begin{array}{l}\text { Antidepressant } \\
\text { drug }\end{array}$ & $\begin{array}{l}\text { Frequency of anti- } \\
\text { depressant-induced } \\
\text { switching to mania/ } \\
\text { hypomania, \% }\end{array}$ & $\begin{array}{l}\text { Equilibrium dissociation } \\
\text { constants for muscarinic } \\
\text { acetylcholine receptors of } \\
\text { human brain, KD } \pm \text { SE (nM) }\end{array}$ \\
\hline Amitriptyline & 42 & $18 \pm 1$ \\
Imipramine & 40 & $90 \pm 3$ \\
Clomipramine & 35 & $37 \pm 4$ \\
Doxepin & 26 & $80 \pm 6$ \\
Desipramine & 18 & $198 \pm 14$ \\
Mianserin & 10 & $820 \pm 110$ \\
Maprotiline & 5 & $570 \pm 120$ \\
Nomifensine & 9 & 250,000 \\
Trazodone & 9 & 324,000 \\
\hline
\end{tabular}

itriptyline, imipramine and clomipramine, in proportion to their specific muscarinic receptor affinity [23] (table 3). These data suggest the significant role the anticholinergic effects of TCA play in causing mood conversion and reflect the original proposal of Janowsky et al. [24] on the cholinergic-adrenergic balance in mood disorder.

A recent study showed that a typical anticholinergic agent, scopolamine, can exert an antidepressant effect [25], and it may be conceivable that it can also induce a mood conversion. However, in light of the small number of subjects treated so far with scopolamine and the short period of such treatment, it is impossible to judge whether this drug has any mood-converting potential.

Limitations to our analysis may involve the fact that our observation periods were quite short and included only inpatients. The study was retrospective and not based on randomized trials. Also, the group taking nonTCAs and the group using mood stabilizers were relatively small. However, the strength of our study lies in the substantial number of patients analyzed and the naturalistic observation that mimics clinical practice.

\section{Acknowledgement}

We thank Prof. Stanisław Pużyński from the Institute of Psychiatry and Neurology, Warsaw, for his valuable comments on the manuscript. 


\section{References}

1 Wehr TA, Goodwin FK: Can antidepressants cause mania and worsen the course of affective illness? Am J Psychiatry 1987; 144:14031411.

-2 Goldberg JF, Truman CJ: Antidepressant-induced mania: an overview of current controversies. Bipolar Disord 2003;5:407-420.

-3 Chun BJDH, Dunner DL: A review of antidepressant-induced hypomania in major depression: suggestions for DSM-V. Bipolar Disord 2004;6:32-42.

4 Angst J: Switch from depression to mania: a record study over decades between 1920 and 1982. Psychopathology 1985;18:140-154.

$\checkmark 5$ Coryell W, Solomon D, Turvey C, Keller M, Leon AC, Endicott J, Schettler P, Judd L, Mueller T: The long-term course of rapid-cycling bipolar disorder. Arch Gen Psychiatry 2003;60:914-920.

6 Gijsman HJ, Geddes JR, Rendell JM, Nolen WA, Goodwin GM: Antidepressants for bipolar depression: a systematic review of randomized, controlled trials. Am J Psychiatry 2004;161:1537-1547.

$>7$ Carlson GA, Finch SJ, Fochtman LJ, Qing Y, Qing W, Naz B: Antidepressant-associated switches from depression to mania in severe bipolar disorder. Bipolar Disord 2007;9:851859.

8 Sachs GS, Nierenberg AA, Calabrese JR, Marangell LB, Wisniewski SR, Gyulai L, Friedman ES, Bowden CL, Fossey MD, Ostacher MJ, Ketter TA, Patel J, Hauser P, Papport D, Martinez JM, Allen MH, Miklowitz DJ, Otto MW, Dennehy EB, Thase ME: Effectiveness of adjunctive antidepressant treatment for bipolar depression. N Engl J Med 2007;356: 1711-1722.
-9 Visser HM, Van Der Mast RC: Bipolar disorder, antidepressants and induction of hypomania or mania. A systematic review. World J Biol Psychiatry 2005;6:231-241.

10 Peet M: Induction of mania with selective serotonin re-uptake inhibitors and tricyclic antidepressants. Br J Psychiatry 1994;164: 549-550.

11 Goodwin FK, Jamison KR: Manic-Depressive Illness. Bipolar Disorders and Recurrent Depression, ed 2. New York, Oxford University Press, 2007.

12 Boerlin HL, Gitlin MJ, Zoellner LA, Hammen CL: Bipolar depression and antidepressant-induced mania: a naturalistic study. J Clin Psychiatry 1998;59:374-379.

13 Bottlender R, Rudolf D, Strauss A, Möller HJ: Antidepressant-associated maniform states in acute treatment of patients with bipolar-I depression. Eur Arch Psychiatry Clin Neurosci 1998;6:296-300.

14 Henry C, Sorbara F, Lacoste J, Gindre C, Leboyer M: Antidepressant-induced mania in bipolar patients: identification of risk factors. J Clin Psychiatry 2001;62:249-255.

15 Stoll AL, Mayer PV, Kolbrener M, Goldstein E, Suplit B, Lucier J, Cohen BM, Tohen M: Antidepressants-associated mania: a controlled comparison with spontaneous mania. Am J Psychiatry 1994;151:1642-1645.

16 Sachs GS, Lafer B, Stoll AL: A double blind trial of bupropion versus desipramine for bipolar depression. J Clin Psychiatry 1994;55: 391-393.
17 Ghaemi SN, Hsy DJ, Soldani F, Goodwin FK: Antidepressants in bipolar disorder: the case for caution. Bipolar Disord 2003;5:421-433.

18 Diagnostic and Statistical Manual of Mental Disorders. DSM-IV. Washington, American Psychiatric Association, 1994.

19 Altshuler LL, Post RM, Leverich GS, Mikalaukas K, Rosoff A, Ackerman L: Antidepressants-induced mania and cycle acceleration: a controversy revisited. Am J Psychiatry 1995;152:1130-1138.

20 Bunney WE: Psychopharmacology of the switch process in affective illness; in Lipton MA, Kellam KF (eds): Psychopharmacology: A Generation of Progress. New York, Raven Press, 1978.

21 Berk M, Dodd S, Kauer-Sant'Anna M, Malhi GS, Malhi GS, Bourin M, Kapczinski F, Norman T: Dopamine dysregulation syndrome: implications for a dopamine hypothesis of bipolar disorder. Acta Psychiatr Scand Suppl 2007;434:41-49.

22 Koszewska I, Pużyński S: Transition from the depressive stage to the manic stage during the treatment with antidepressive drugs (in Polish). Psychiatr Pol 1991;25:76-82.

$>23$ El-Fakahany E, Richelson E: Antagonism by antidepressants of muscarinic acetylcholine receptors of human brain. Br J Pharmacol 1983;78:97-102.

24 Janowsky DS, El-Yousef MK, Davis JM, Sekerke HJ: A cholinergic-adrenergic hypothesis of mania and depression. Lancet 1972;ii:632-635.

25 Furey ML, Drevets WC: Antidepressant efficacy of the antimuscarinic drug scopolamine: a randomized, placebo-controlled trial. Arch Gen Psychiatry 2006;63:11211129. 